\title{
FATIGUE BEHAVIOR OF PEARLITIC S.G. CAST IRONS AFTER LASER SURFACE HEAT TREATMENTS
}

\author{
Y. GUAN, D. PANTELIS, D. CHAMBOLLE, S. PARENT-SIMONIN* and \\ Ph. POUPEAU \\ Laboratoire MSS/MAT, URA CNRS $n^{\circ} 850$, Ecole Centrale de Paris, Grande Voie des Vignes, \\ F-92295 Châtenay-Malabry cedex, France \\ *Centre Technique des Industries de la Fonderie, Division Fontes, 44 av. de la Division Leclerc, \\ F.92312 Sèvres cedex, France
}

\begin{abstract}
The laser transformation hardening does not improve the fatigue resistance of two pearlitic S.G. cast irons, using as surface preparation BN coating, sandblasting or phosphatation. On the treated surface, the initial pearlite is transformed into martensite. In the treated layer, further under the treated surface, a martensitic microstructure with traces of incompletely dissolved cementite can be observed. A bidimensional numerical heat transfer model has been developed for surface transformation determination. This model allows the use of temperature dependent thermophysical properties, spatial energy distribution of the laser beam and convective heat losses. The agreement between the calculated results and the experimental results depends on the value of the ratio $\frac{P}{\sqrt{V}}$.
\end{abstract}

\section{1.- INTRODUCTION.}

High power laser surface treatments improve the surface properties of metallic materials and they have been developed for many industrial applications. Spheroildal graphite (S.G.) cast irons, which have large applications in industry, specially in car industry, are often used with surface treatments. Many pieces surface heat treated, need high resistance to fatigue, such as crankshaft, camshaft, gears, etc.. Unfortunately, few fatigue data are available for laser treated cast irons. This study has the aim to investigate the influence of laser surface hardening on the fatigue behavior of two pearlitic S.G. cast irons, namely FGS 5024 and FGS 5009 . The microstructures and the fatigue properties of these two cast irons were studied after laser surface transformation hardening, and further, a heat transfer model was set up to calculate the thermal field obtained during laser surface hardening without any remelting.

\section{2.- EXPERIMENTAL DETAILS.}

Two spheroildal graphite cast irons were used for this investigation, named FGS 5009 and FGS 5024 . The great difference between these two cast irons is their copper content. The chemical compositions of these two cast irons are shown in table 1.

Table 1. Chemical compositions of the cast irons :

\begin{tabular}{|c|c|c|c|c|c|c|c|}
\hline Element & $\mathrm{C}$ & $\mathrm{Si}$ & $\mathrm{Mn}$ & $\mathrm{S}$ & $\mathrm{P}$ & $\mathrm{Cu}$ & $\mathrm{Mg}$ \\
\hline $\begin{array}{c}\text { FGS 5009 } \\
\text { (mass \%) }\end{array}$ & 3.60 & 2.19 & 0.46 & $<0.005$ & 0.033 & 0.021 & 0.069 \\
\hline $\begin{array}{c}\text { FGS 5024 } \\
\text { (mass \%) }\end{array}$ & 3.53 & 2.20 & 0.50 & $<0.005$ & 0.03 & 0.75 & 0.048 \\
\hline
\end{tabular}


These two alloys have a micrographic structure with graphite nodules in a pearlitic matrix and a little ferrite. Their average microhardness is respectively 300 HV for FGS 5009 and 250 HV for FGS 5024 . These cast irons were machined into specimens measuring $4 \times 8 \times 60 \mathrm{~mm}$ for convenience of the three points fatigue test.

in order to increase energy absorption, specimens surfaces were initially milled and sandblasting was used before laser treatment or specimens surfaces were grinded and BN coating and phosphatation was used in this case.

The treatements were performed with a $3.2 \mathrm{~kW}$, continuous $\mathrm{CO}_{2}$ laser (CILAS 4000). The laser beam was focused by a mirror that can be put out of shape in order to get a uniform energy distribution. This mirror was adjusted so that the whole surface of the specimen could be treated in one pass. $\mathrm{CO}_{2}$ gas was used to protect the specimen surface during laser treatment.

The specimens treated by laser were examined with an optical microscope and a Scanning Electron Microscope (SEM) to investigate the microstructural transformations. Microhardness was measured on optical microscope with a $80 \mathrm{~g} \mathrm{load}$.

To investigate the modification of the fatigue behavior, laser treated specimens and non treated specimens were used in fatigue tests (three points flexion fatigue test) with a $30 \mathrm{~Hz}$ frequency. The ratio of the minimum to the maximum of the applied stress was 0.15 . The specimen was set up with the laser treated surface always at the bottom of the specimen, subject to tensile ștress. The fractography of fatigue cracks was obtained with a SEM.

\section{RESULTS AND DISCUSSION.}

\subsection{Microstructure and microhardness of the laser treated layer.}

\subsubsection{Specimens with milled surface.}

First, the specimens of the two cast irons with milled surfaces were used for the laser surface treatment. Figure 1(a) gives the electronic micrographs showing the microstructures of the laser treated layer and of the matrix of the iron FGS 5009 (without copper). Pearlite was transformed into martensite in the laser treated layer. Microhardness of the laser treated layer is about $1,000 \mathrm{HV}$.

However, in the cast iron FGS 5024 (with copper) microstructures lamellae can be seen in the laser treated zone (figure 1(b)). These white lamellae correspond to the cementite existing in the initial pearlite which were not completely dissolved during laser heating. At the interface between the HAZ and the substrate, it is observed clearly that these lamellae are continuous from the substrate to the laser treated zone. In this case, this microstructure with lamellae can be also observed near the laser treated surface. This kind of microstructure has about a $900 \mathrm{HV}$ microhardness, which is lower than that of the laser treated zone of the iron FGS 5009.

The case depth was defined as the largest distance from the treated surface to the interface between the HAZ and the base metal. The case depth can achieve $0.3 \mathrm{~mm}$ according to conditions of laser surface treatment. Microhardness in the laser treated zone is perfectly uniform.

\subsubsection{Specimens with grinded surface.}

After laser surface treatment, the microstructure of the laser affected layer presents the same characteristics for both preparations. The microstructures vary with the distance from the laser treated surface. Near the surface, the initial pearlite is transformed into martensite Far away from the surface but near the interface with the base metal the duration of the stay at a temperature above the $A_{C 1}$ point was not long enough to dissolve completely the cementite of the initial pearlite. Microstructure with residual lamellae of cementite is observed in the laser treated layer. But the lamellae in the HAZ are thinner than those in the substrate. Figure 2 represents microstructure between two partially dissolved lamellae of cementite with high magnification. This microstructure consist of martensite and residual ferrite. The same structures had been already observed in laser treated gray cast iron and chromium steel $[1,2]$. Microhardness of the laser treated layer is relatively uniform and is about $800 \mathrm{HV}$. 


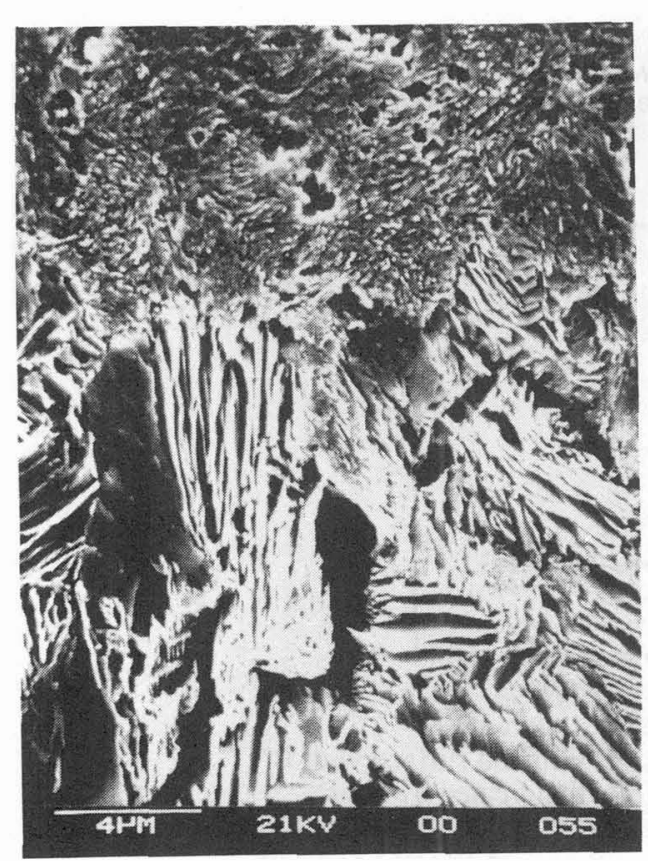

(a)
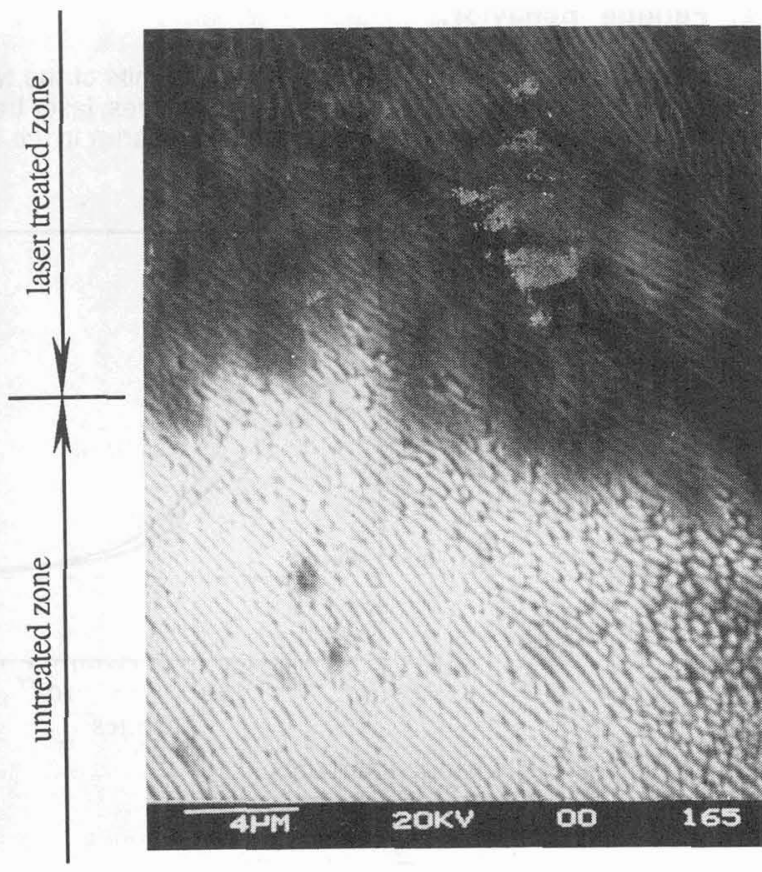

(b)

Fig.1.- Microstructures of the transition zone of S.G. cast irons, between the laser treated zones and the untreated matrix (milled surface with sandblasting).

(a) : S.G. cast iron 5009

(b) : S.G. cast iron 5024

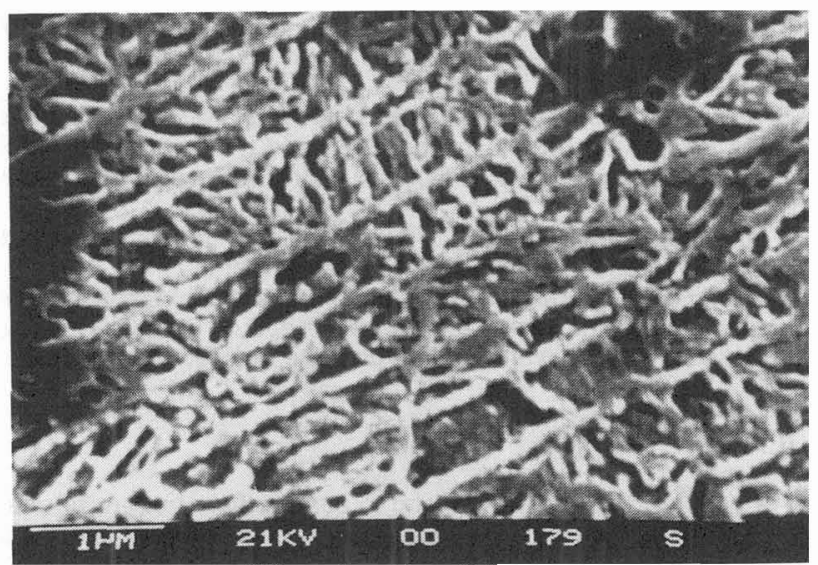

Fig.2.- Microstructure between two partially dissolved lamellae of cementite (S.G. cast iron 5024, grinded surface with phosphatation). 


\subsection{Fatigue behavior.}

The laser surface hardening lowers the fatigue limits of the two cast irons. As an example, the best results are shown on figure 3 . Note that at high stress amplitudes, laser treated specimens crack earlier than those untreated. This phenomenon shows that fatigue cracks start earlier in the laser hardened specimens than in untreated ones at the same applied stress amplitudes.

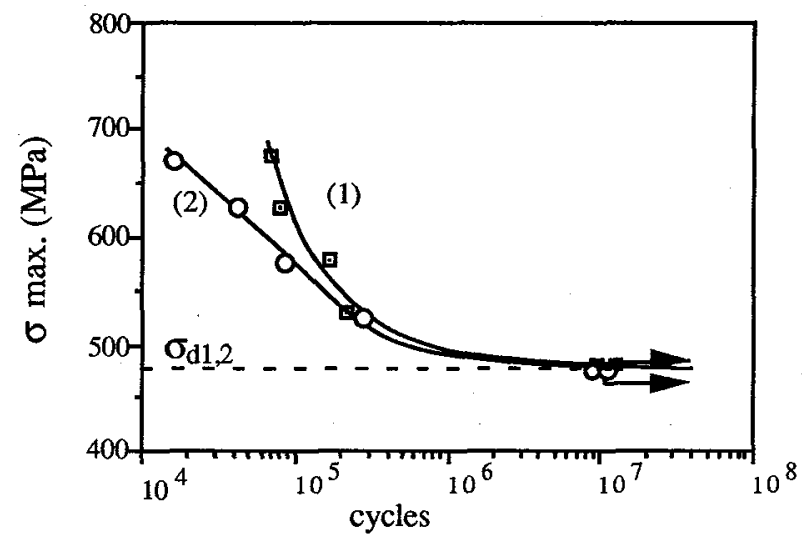

(1) Grinded surfaces

$$
\begin{array}{ll}
\square \rightarrow & \text { Uncracked specimens } \\
\text { - } & \text { Cracked specimens } \\
& \sigma_{\mathrm{d} l}=480 \mathrm{MPa}
\end{array}
$$

(2) Grinded surface with BN coating treated by laser.

$$
\begin{aligned}
& \text { Uncracked specimens } \\
& \text { Cracked specimens } \\
& \sigma_{\mathbb{D} Q}=480 \mathrm{MPa}
\end{aligned}
$$

Fig.3.- $\sigma-N$ curves for S.G. cast iron 5024 in untreated and laser hardened conditions (Surface preparation : $B N$ coating). $\sigma_{d}$ is fatigue limit.

In general, hardened surface layer improves fatigue properties. In case of laser hardening of S.G cast irons, there are nodules of graphite in the hardened surface layer. These nodules play the role of notches in the surface. Unfortunately, martensite in laser treated layer is very sensible to notch effect. So laser treated specimens crack earlier in fatigue tests.

On the other hand, there is a little ferrite in the matrix of the cast irons around the graphite nodules which is melted during laser heating because of eutectic interaction between this ferrite and the graphite of the nodules. This melting of ferrite is not favorable for the creation of compressive stresses in the laser treated layer. So it is harmful to improvement of fatigue properties.

Several investigators have studied fatigue properties of cast irons after laser surface hardening or remelting [3, 4]. No one could succeed in improving fatigue resistance so far by this method.

No evidence of the crack initiation could be observed on fatigue fractured surfaces of laser treated cast irons. In the three points fatigue tests, crack starts in general near a graphite nodule at the surface where the amplitude of the applied stress is the greatest, and it grows toward another graphite nodule, and so on.

\section{THERMAL CALCULATION.}

In order to predict results of laser surtace hardening and to control them better, thermal field existing during and after the treatment was calculated. A bidimensionnal numerical heat transfer model was used in this study for laser surface hardening of the cast irons. The calculated case depth can be obtained from results of thermal field calculation [5]. Case depth was defined as the distance from the treated surface to the position where the maximal temperature was higher than the $A_{C 1}$ point.

In order to develop the mathematical model, the laser surface hardening process is physically defined as follows :

A laser beam strikes the upper surface of a specimen moving in direction $x$. At the same time, there are heat losses at the upper surface and on all the side surfaces by convection between the specimen and the surrounding atmosphere. The bottom temperature is assumed to remain at room temperature.

In the numerical solution used in this study, it was possible to take into account the variation of the thermophysical properties with temperature. In order to obtain a better accuracy in the heat flow calculation, a grid mesh with variable areas was employed. In other words, the mesh areas were kept small where the high temperature gradients were expected, i.e., near the top surface of the specimen. 
Spatial energy distribution of laser beam could be considered. Laser beam was separated in three uniform parts according to its real energy distribution. The calculation was divided into 40 sequences which were equal to the number of segments of the grid mesh on the treated surface. In the first sequence, the laser beam strikes the three first segments. In the second sequence, the laser beam strikes the segments with numbers $2,3,4$, and so on (figure 4). By this way, the velocity of the laser beam moving at a given speed on the top surface of the specimen was introduced in the solution.

Figure 5 shows the distribution of the calculated case depth versus $\frac{P}{\sqrt{V}}$ for the S.G. cast iron 5024 with milled surfaces and sandblasting for surface preparation. The absorptivities used in the calculation were 0.2 and 0.25 . Note that for a given absorptivity the difference between calculated and experimental results varies while increasing $\frac{P}{\sqrt{V}}$ The line of the experimental results crosses the two lines of calculated results with absorptivity 0.2 and 0.25 . This phenomenon shows that absorptivities of specimens decreases while increasing $\frac{P}{\sqrt{V}} \cdot$ Inversely, the absorptivities can be defined by thermal calculations.
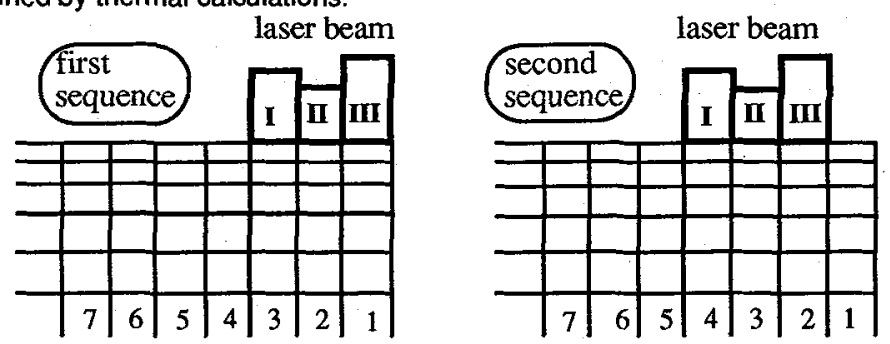

$1,2,3 \ldots:$ number of segments

Fig.4.- Introduction of the laser moving.

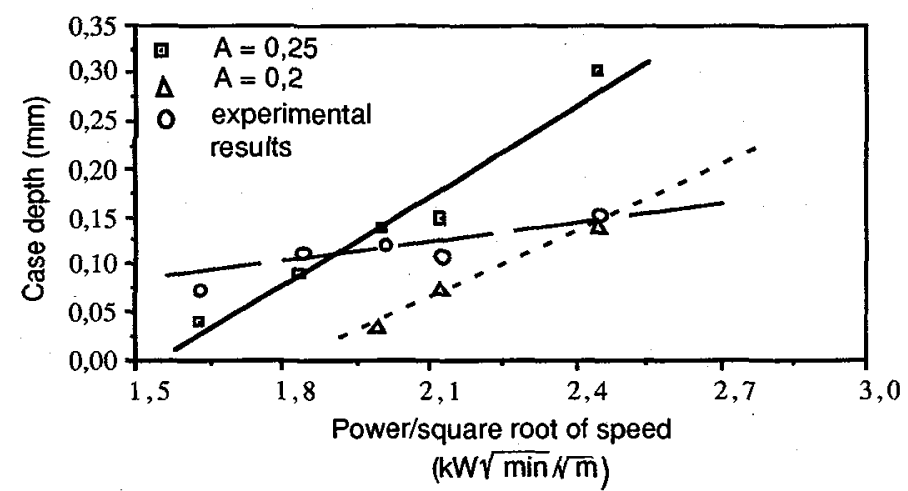

Fig.5.- Comparison of the calculated and the experimental results for case depth of S.G. cast iron 5024 .

The study of the laser surface treatment of cast iron with a laser beam focused by a lens shows that the laser affected area on the treated surface increases while increasing $\frac{P}{\sqrt{V}}$ [5]. So the reduction of the absorptivities with $\frac{P}{\sqrt{V}}$ is attributed to the change of the laser affected area on the top surface. Taking into account the changes of laser affected area, the calculation led to an excellent agreement between the calculated and the experimental results [5]. In this study, it was impossible to measure the laser affected area of the whole surface of a specimen treated by laser beam with a continuous pass, because the beam width was larger than the specimen width. 


\section{CONCLUSIONS.}

1. Laser surface treatment of the pearlitic cast irons produces a hardened surface layer with a microhardness from 800 to $1000 \mathrm{HV}$. The case depth is up to $0.3 \mathrm{~mm}$ according to treatment conditions.

2. For specimens with milled surfaces, laser surface treatment of cast iron FGS 5009 (without copper) produces a martensitic microstructure in the treated layer. A microstructure with lamellae was obtained in laser treated layer of cast iron FGS 5024 (with copper).

3. For specimens with grinded surfaces, the microstructural characteristics change with the depth from the treated surface. Near the treated surface, pearlite is transformed into martensite. Far away from the treated surface in the hardened layer, the microstructure with lamellae is observed.

4. Laser surface hardening of the two cast irons studied cannot improve fatigue resistance.

5. For a given absorptivity, difference between calculated and experimental case depth varies with $\frac{P}{\sqrt{V}}$. To obtain a good agreement, the change of the laser affected area according to $\frac{P}{\sqrt{V}}$ has to be taken into account. This can be realized by introducing the measured laser affected area or by modifying the absorptivities according to $\frac{P}{\sqrt{V}}$.

6. From thermal calculation, the absorptivities of laser treated cast irons can be indirectly defined.

\section{REFERENCES}

[1] F. FOUQUET, L. RENAULD, C. NICOT et J. MERLIN "Traitement Thermique Superficiel d'une Fonte Grise Perlitique par Faisceau Laser" Mémoires et Etudes Scientifiques de la Revue de Métallurgie, $n^{\circ}$ 1, Janvier 1991, p.23-31.

[2] J.R. BRADLEY and S. KIM "Laser Transformation Hardening of Iron-carbon and Iron-carbon-chromium Steels" Metallurgical Transactions A, Vol. 19A, August 1988, p.2013.

[3] P.A. MOLIAN "Fatigue Characteristics of Laser Surface Hardened Cast Irons" Journal of Engineering Materials and Technology, Vol.109, July 1987, p.179-187.

[4] H. W. BERGMANN and M. YOUNG

"Properties of Laser Melted S.G. Iron"

2nd International Conference on laser in Manufacturing (LIM-2), Birmingham, 26-28, March 1985, p.109-118.

[5] Y. GUAN

"High Power Laser Surface Treatments of S.G. Cast Irons, Influence on Microstructure and Fatigue Resistance, Calculation of the Thermal Field", Doctor degree thesis, Ecole Centrale Paris, Châtenay-Malabry, April 1991. 